\title{
Development and validation of risk prediction equations to estimate future risk of blindness and lower limb amputation in patients with diabetes: cohort study
}

\author{
Julia Hippisley-Cox, Carol Coupland
}

Division of Primary Care,

Nottingham University,

Nottingham NG2 7RD, UK

Correspondence to:

J Hippisley-Cox

Julia.hippisley-cox@nottingham.

ac.uk

Additional material is published online only. To view please visit the journal online (http://dx.doi. org/10.1136/bmj.h5441) Cite this as: $B M J$ 2015;351:h5441 doi: 10.1136/bmj.h5441

Accepted: 29 September 2015

\section{ABSTRACT}

STUDY QUESTION

Is it possible to develop and externally validate risk prediction equations to estimate the 10 year risk of blindness and lower limb amputation in patients with diabetes aged $25-84$ years?

\section{METHODS}

This was a prospective cohort study using routinely collected data from general practices in England contributing to the QResearch and Clinical Practice Research Datalink (CPRD) databases during the study period 1998-2014. The equations were developed using 763 QResearch practices ( $n=454575$ patients with diabetes) and validated in 254 different QResearch practices ( $n=142$ 419) and 357 CPRD practices ( $n=206050)$. Cox proportional hazards models were used to derive separate risk equations for blindness and amputation in men and women that could be evaluated at 10 years. Measures of calibration and discrimination were calculated in the two validation cohorts.

\section{STUDY ANSWER AND LIMITATIONS}

Risk prediction equations to quantify absolute risk of blindness and amputation in men and women with diabetes have been developed and externally validated. In the QResearch derivation cohort, 4822 new cases of lower limb amputation and 8063 new cases of blindness occurred during follow-up. The risk equations were well calibrated in both validation cohorts. Discrimination was good in men in the external CPRD cohort for amputation (D statistic 1.69, Harrell's C statistic 0.77) and blindness (D statistic 1.40, Harrell's C statistic 0.73 ), with similar results in women and in the QResearch validation cohort. The algorithms are based on variables that patients are likely to know or that are routinely recorded in general practice computer systems. They can be used to identify patients at high risk for prevention or further

\section{WHAT IS KNOWN ON THIS TOPIC}

Patients with type 1 or type 2 diabetes are at increased risk of blindness and amputation but generally do not have an accurate assessment of the magnitude of their individual risk

\section{WHAT THIS PAPER ADDS}

New risk prediction algorithms for blindness and amputation have been developed and externally validated

These calculate the absolute risk of developing these complications over a 10 year period in patients with diabetes, taking account of their individual risk factors

The web calculator to calculate the absolute risk of complications among patients with diabetes is available at qdiabetes.org/amputation-blindness/index.php

assessment. Limitations include lack of formally adjudicated outcomes, information bias, and missing data.

\section{WHAT THIS STUDY ADDS}

Patients with type 1 or type 2 diabetes are at increased risk of blindness and amputation but generally do not have accurate assessments of the magnitude of their individual risks. The new algorithms calculate the absolute risk of developing these complications over a 10 year period in patients with diabetes, taking account of their individual risk factors.

FUNDING, COMPETING INTERESTS, DATA SHARING $\mathrm{JH}-\mathrm{C}$ is co-director of QResearch, a not for profit organisation which is a joint partnership between the University of Nottingham and Egton Medical Information Systems, and is also a paid director of ClinRisk Ltd. CC is a paid consultant statistician for ClinRisk Ltd.

\section{Introduction}

Diabetes is associated with macrovascular complications including an increased risk of coronary heart disease or stroke and microvascular complications such as kidney failure, blindness, and amputation. ${ }^{1-3}$ Intensive control of risk factors such as glycated haemoglobin and systolic blood pressure lowers the incidence of microvascular disease in type 1 and type 2 diabetes. ${ }^{24-6}$ Tight control of blood parameters is the cornerstone of national guidance, national audits, and quality improvement incentives schemes. ${ }^{37-9}$ However, patients need good quality information on how likely they are to develop complications and the expected risks and benefits from interventions to reduce the risk, as very few patients are able to quantify this accurately..$^{10}$ Guidelines for cardiovascular disease recommend the use of calculators such as QRISK2 to estimate the absolute risk of cardiovascular disease while taking account of patients' characteristics. ${ }^{7}$ Although QRISK2 and related tools can be used to assess individualised absolute risk of cardiovascular disease, stroke, and kidney failure in patients with diabetes, ${ }^{11-13}$ no tools are available to calculate the risk of other complications such as amputation or blindness. This is important because these are the complications that patients with diabetes fear most and that most impair their quality of life. ${ }^{14}$ They are also the complications for which patients are most likely to overestimate their risk and overestimate the benefits of intensive treatment. ${ }^{10}$

The UK Prospective Diabetes Study (UKPDS) is a source of information on the incidence of amputation and blindness, based on a cohort that originated from a trial of 5102 patients aged 25-65 with newly diagnosed 
type 2 diabetes recruited between 1977 and 1991 and followed up until 1997.5 However, very few patients in the cohort developed blindness $(\mathrm{n}=116)$ or needed amputation $(n=45)$ during follow-up. ${ }^{16}$ Also, the generalisability of the cohort is limited because of its historical nature and exclusion of people aged over 65 and those with various comorbidities.

We aimed to derive and externally validate risk prediction equations to quantify absolute 10 year risks of blindness and amputation in patients with diabetes by using variables recorded in their primary care electronic record. Our intention was to provide a readily accessible method to quantify an individual patient's absolute risks of blindness and amputation to complete a risk profile for patients with diabetes. This information could be used to provide better information for patients and doctors and to prioritise those patients at the highest levels of risk to inform treatment decisions and for closer management of modifiable risk factors.

\section{Methods}

\section{Study design and data source}

We did a cohort study using the UK QResearch database (version 39, www.qresearch.org) to derive and validate the risk equations in a large population of primary care patients with diabetes. We also carried out an external validation using the Clinical Practice Research Datalink (CPRD) database. QResearch is a continually updated, patient level, pseudonymised database with data extending back to 1989. It includes clinical and demographic data from more than 1000 general practices covering a population of more than 20 million patients, collected in the course of routine healthcare. The primary care data include demographic information, diagnoses, prescriptions, referrals, laboratory results, and clinical values. Diagnoses, symptoms, and clinical values are recorded using the Read code classification. ${ }^{15}$ QResearch has been used for a wide range of clinical research, including the development and validation of risk prediction models. ${ }^{11216}$ The primary care data are linked at individual patient level to Hospital Episode Statistics (HES) and to mortality records from the Office for National Statistics (ONS). HES provides details of all National Health Service (NHS) inpatient admissions since 1997, including primary and secondary causes coded using the ICD-10 (international classification of diseases, 10th revision) classifications and operations and procedures coded using the fourth revision of the Office of Population, Censuses and Surveys Classification of Surgical Operations and Procedures (OPCS-4). ONS provides details of all deaths in England with primary and underlying causes, also coded using the ICD10 classification. Patients' records are linked using a project specific pseudonymised NHS number, which is valid and complete for $99.8 \%$ of primary care patients, $99.9 \%$ of ONS mortality records, and $98 \%$ of hospital admissions records. ${ }^{1}$

We included all QResearch practices in England that had been using their Egton Medical Information Systems (EMIS) computer system for at least a year. The EMIS computer system is the predominant commercial system used by $55 \%$ of family doctors in the United Kingdom for routine recording of health data for individual patients (www.emishealth.com/). We randomly allocated three quarters of these practices to the derivation dataset and the remaining quarter to a validation dataset. In both datasets, we identified open cohorts of patients aged 25-84 years registered with eligible practices between 1 January 1998 and 31 July 2014. We then selected patients with diabetes if they had a Read code for diabetes or more than one prescription for insulin or oral hypoglycaemics. We classified patients as having type 1 diabetes if their diabetes had been diagnosed before they were 35 years of age and was treated with insulin; ${ }^{17}$ we classified all remaining patients as having type 2 diabetes. We excluded patients without a postcode related deprivation score. We determined an entry date to the cohort for each patient, which was the latest of the date of diagnosis of diabetes, 25th birthday, date of registration with the practice plus one year, date on which the practice computer system was installed plus one year, and the beginning of the study period (1 January 1998). Patients were censored at the earliest date of the diagnosis of the relevant complication (blindness or lower limb amputation), death, de-registration with the practice, last upload of computerised data, or the study end date (1 August 2014).

We did an external validation using general practices in England contributing to the CPRD database. This is a similar database to QResearch except that it is derived from practices using a different clinical computer system. We used the subset of 357 CPRD practices linked to ONS mortality and hospital admission data. We used the same definitions for selecting a validation cohort as for QResearch, except that the study end date was 1 August 2012, the latest date for which linked data were available.

\section{Outcomes}

We had two outcomes of interest: lower limb amputation based on a recorded diagnosis or procedure (including above knee and below knee amputations) and blindness (including blindness in one or both eyes, registered blind, severe visual impairment). We classified patients as having the outcome if a record of the relevant diagnosis was present in their primary care record, their linked hospital record, or the ONS mortality record. We used Read codes to identify recorded diagnoses from the primary care record. We used ICD-10 clinical codes and OPCS-4 procedure codes to identify incident cases of each outcome from hospital records. ${ }^{18}$ We used ICD-10 codes to identify cases from either the primary or underlying cause of death as recorded on the linked ONS mortality record. The web appendix gives a list of the Read codes, OPCS-4, and ICD-10 codes used. We used the earliest recorded date of the relevant diagnosis or procedure on any of the three data sources as the index date for the diagnosis. Patients with lower limb amputation at baseline were excluded from the cohort for the analyses of lower limb amputations during follow-up and similarly for blindness. 


\section{Predictor variables}

We examined the following predictor variables based on established risk factors for vascular disease: ${ }^{1}$ 611 19-21 age at cohort entry (continuous), ${ }^{22}$ type of diabetes (type 1 or type 2 ), ${ }^{2}$ number of years since diagnosis of diabetes $(<1,1-3,4-6,7-10, \geq 11$ years), smoking status (non-smoker; ex-smoker; light (1-9 cigarettes/day), moderate (10-19/day), heavy ( $\geq 20 /$ day) smoker), ${ }^{22}$ ethnic group (white/not recorded, Indian, Pakistani, Bangladeshi, other Asian, black Caribbean, black African, Chinese, other), ${ }^{19}$ Townsend deprivation score (continuous), ${ }^{1121}$ glycated haemoglobin $\left(\mathrm{HbA}_{1 \mathrm{c}}\right.$ $\mathrm{mmol} / \mathrm{mol}$, continuous), ${ }^{122-24}$ systolic blood pressure (mm $\mathrm{Hg}$, continuous), ${ }^{622}$ body mass index $\left(\mathrm{kg} / \mathrm{m}^{2}\right.$, continuous), total serum cholesterol/high density lipoprotein cholesterol ratio (continuous), ${ }^{11}$ atrial fibrillation, ${ }^{11}$ congestive cardiac failure, cardiovascular disease, treated hypertension, ${ }^{11}$ peripheral vascular disease, ${ }^{21}$ chronic renal disease, rheumatoid arthritis, ${ }^{11}$ and proliferative retinopathy or maculopathy.

For each of the continuous clinical variables, we used the value recorded closest to the baseline cohort entry date out of all those recorded before the baseline date or within the six months after this date. All other predictor variables were based on the latest information recorded in the primary care record before entry to the cohort. The United Kingdom now uses the SI unit of millimoles of $\mathrm{HbA}_{1 \mathrm{c}}$ per mole of haemoglobin ( $\mathrm{mmol} / \mathrm{mol}$ ) instead of the percentage. ${ }^{25}$ We converted historical values recorded in percentages to $\mathrm{mmol} / \mathrm{mol}^{26}$

\section{Derivation of models}

We used established methods to develop risk prediction equations for lower limb amputation and blindness in the derivation cohort. ${ }^{112}$ We derived separate equations for men and women. Initially, we used complete case analyses to derive fractional polynomial terms to model non-linear risk relations with continuous variables if appropriate (age, body mass index, systolic blood pressure, serum cholesterol/high density lipoprotein ratio, $\left.\mathrm{HbA}_{1 \mathrm{c}}\right) .{ }^{27}$ We then used multiple imputation to replace missing values for continuous values and smoking status and used these values in our main analyses. ${ }^{28-30}$ We included all the candidate predictor variables listed above in the multiple imputation models, along with the log of survival time and the censoring indicator. We log transformed body mass index, $\mathrm{HbA}_{1 \mathrm{c}}$, cholesterol, and high density lipoprotein cholesterol before imputation, as they had positively skewed distributions. We carried out 10 imputations to improve the statistical efficiency of the estimates. ${ }^{31}$ We used Cox's proportional hazards models to estimate the coefficients for each risk factor for both of our outcomes by using the fractional polynomial terms obtained from the complete case analyses. We used Rubin's rules to combine the regression coefficients across the imputed datasets. ${ }^{32}$ We fitted full models initially and then retained variables if they had a hazard ratio below 0.80 or above 1.20 (for binary variables) and were statistically significant at the 0.05 level. We examined interactions between predictor variables and age and included these if they were significant and plausible (that is, similar in direction for both men and women and consistent with the literature) and they improved model fit. We assessed model fit by measuring the Akaike information criterion and bayesian information criterion values for each imputed set of data.

We used the regression coefficients for each variable from the final model as weights, which we combined with the baseline survivor function evaluated up to 15 years to derive risk equations over a period of 15 years of follow-up. ${ }^{33}$ This enabled us to derive absolute risk estimates for each year of follow-up, with a specific focus on 10 year risk estimates. We estimated the baseline survivor function on the basis of zero values of centred continuous variables, with all binary predictor values set to zero.

\section{Validation of models}

We used multiple imputation in the two validation cohorts to replace missing values for continuous variables and smoking status. We carried out 10 imputations. We applied the risk equations for men and women obtained from the derivation cohort to the validation cohorts and calculated measures of discrimination. We calculated $\mathrm{R}^{2}$ values (explained variation in time to diagnosis of outcome), ${ }^{34} \mathrm{D}$ statistics (a measure of discrimination for which higher values indicate better discrimination), 35 and Harrell's C statistics (an extension of the receiver operating characteristic statistic to survival data) $)^{36}$ over 10 years and combined these model performance measures across imputed datasets by using Rubin's rules. We assessed calibration, comparing the mean predicted risks at 10 years with the observed risk by 10th of predicted risk. The observed risks were obtained using Kaplan-Meier estimates evaluated at 10 years. We applied the risk equations to the validation cohorts to define thresholds for the $10 \%$ and $20 \%$ of patients at the highest estimated risk at 10 years and calculated sensitivity, specificity, and observed risks for these thresholds.

We used all the available data for eligible patients on each database to maximise power and generalisability. We used Stata (version 13.1) for all analyses. We adhered to the TRIPOD statement for reporting. ${ }^{37}$

\section{Patient involvement}

Patients were not involved in setting the research question, the outcome measures, or the design or implementation of the study. Patient representatives from the QResearch Advisory Board have written the information for patients on the QResearch website about the use of the database for research. They have also advised on dissemination, including the use of lay summaries describing the research and its results.

\section{Results}

\section{Overall study population}

Overall, 1017 QResearch practices in England met our inclusion criteria, of which 763 were randomly assigned to the derivation dataset; the remaining 254 practices 


\begin{tabular}{|c|c|c|c|c|c|c|}
\hline \multirow[b]{2}{*}{ Characteristics } & \multicolumn{2}{|c|}{ QResearch derivation cohort } & \multicolumn{2}{|c|}{ QResearch validation cohort } & \multicolumn{2}{|c|}{ CPRD validation cohort } \\
\hline & Women $(n=199$ 679) & Men $(n=254896)$ & Women $(n=62407)$ & Men $(n=80012)$ & Women $(n=90280)$ & Men $(n=115770)$ \\
\hline Type 2 diabetes & $188086(94.2)$ & $241058(94.6)$ & $58852(94.3)$ & $75717(94.6)$ & $85361(94.6)$ & $109540(94.6)$ \\
\hline Type 1 diabetes & $11593(5.8)$ & $13838(5.4)$ & $3555(5.7)$ & $4295(5.4)$ & $4919(5.4)$ & $6230(5.4)$ \\
\hline \multicolumn{7}{|l|}{ Years since diagnosis: } \\
\hline Newly diagnosed ( $<1$ year) & $108040(54.1)$ & $137725(54.0)$ & $34900(55.9)$ & $44412(55.5)$ & $48913(54.2)$ & $62922(54.4)$ \\
\hline $1-3$ years & $33256(16.7)$ & $43790(17.2)$ & $9819(15.7)$ & $12902(16.1)$ & $14912(16.5)$ & $19345(16.7)$ \\
\hline 4-6 years & $18826(9.4)$ & $23855(9.4)$ & $5552(8.9)$ & $7159(8.9)$ & $8283(9.2)$ & $10535(9.1)$ \\
\hline $7-10$ years & $15895(8.0)$ & $19950(7.8)$ & $4824(7.7)$ & $6256(7.8)$ & $7285(8.1)$ & $9255(8.0)$ \\
\hline$>10$ years & $23662(11.9)$ & $29576(11.6)$ & $7312(11.7)$ & $9283(11.6)$ & $10887(12.1)$ & $13713(11.8)$ \\
\hline Mean (SD) age, years & $61.5(14.1)$ & $59.5(13.4)$ & $62(14.0)$ & $59.9(13.3)$ & $62.7(13.7)$ & $60.4(12.9)$ \\
\hline Mean (SD) Townsend score & $0.8(3.4)$ & $0.5(3.4)$ & $0.4(3.3)$ & $0.1(3.2)$ & $0(3.3)$ & $-0.4(3.2)$ \\
\hline Ethnicity recorded: & $150526(75.4)$ & $191204(75.0)$ & $46575(74.6)$ & $59394(74.2)$ & $40151(44.5)$ & $51522(44.5)$ \\
\hline White/not recorded & $164366(82.3)$ & $214557(84.2)$ & $53760(86.1)$ & $70000(87.5)$ & $83962(93.0)$ & $108518(93.7)$ \\
\hline Indian & $6836(3.4)$ & $9027(3.5)$ & $1928(3.1)$ & $2606(3.3)$ & $1503(1.7)$ & $2036(1.8)$ \\
\hline Pakistani & $5011(2.5)$ & $5744(2.3)$ & $854(1.4)$ & $1071(1.3)$ & $778(0.9)$ & $801(0.7)$ \\
\hline Bangladeshi & $5979(3.0)$ & $6731(2.6)$ & $956(1.5)$ & $1028(1.3)$ & $268(0.3)$ & $321(0.3)$ \\
\hline Other Asian & $3134(1.6)$ & $4017(1.6)$ & $1005(1.6)$ & $1393(1.7)$ & $865(1.0)$ & $1083(0.9)$ \\
\hline Caribbean & $5614(2.8)$ & $4653(1.8)$ & $1578(2.5)$ & $1291(1.6)$ & $919(1.0)$ & $768(0.7)$ \\
\hline Black African & 3831 (1.9) & $4654(1.8)$ & $1004(1.6)$ & $1102(1.4)$ & $838(0.9)$ & $891(0.8)$ \\
\hline Chinese & $693(0.3)$ & $719(0.3)$ & $193(0.3)$ & $222(0.3)$ & $138(0.2)$ & $168(0.1)$ \\
\hline Other & $4215(2.1)$ & $4794(1.9)$ & $1129(1.8)$ & $1299(1.6)$ & $1009(1.1)$ & $1184(1.0)$ \\
\hline Smoking status recorded: & $189827(95.1)$ & $243379(95.5)$ & 59409 (95.2) & $76617(95.8)$ & $89107(98.7)$ & $114577(99.0)$ \\
\hline Non-smoker & $118807(59.5)$ & $108368(42.5)$ & $36291(58.2)$ & $33839(42.3)$ & $43414(48.1)$ & $40977(35.4)$ \\
\hline Ex-smoker & $41073(20.6)$ & $83683(32.8)$ & $13572(21.7)$ & $27231(34.0)$ & $14002(15.5)$ & $28100(24.3)$ \\
\hline Light smoker & $16090(8.1)$ & $30116(11.8)$ & $5112(8.2)$ & $9080(11.3)$ & $4879(5.4)$ & $7799(6.7)$ \\
\hline Moderate smoker & $7720(3.9)$ & $10684(4.2)$ & $2512(4.0)$ & $3196(4.0)$ & $9772(10.8)$ & $12756(11.0)$ \\
\hline Heavy smoker & $6137(3.1)$ & $10528(4.1)$ & $1922(3.1)$ & $3271(4.1)$ & $5931(6.6)$ & $11363(9.8)$ \\
\hline Amount smoked not recorded & NA & NA & NA & NA & $11109(12.3)$ & $13582(11.7)$ \\
\hline \multicolumn{7}{|l|}{ Medical conditions at baseline: } \\
\hline Atrial fibrillation & $7995(4.0)$ & $11009(4.3)$ & $2684(4.3)$ & $3626(4.5)$ & $3952(4.4)$ & $5273(4.6)$ \\
\hline Congestive cardiac failure & $6783(3.4)$ & $9986(3.9)$ & $2255(3.6)$ & $3136(3.9)$ & $3504(3.9)$ & $4641(4.0)$ \\
\hline Cardiovascular disease & $31729(15.9)$ & $55262(21.7)$ & $10170(16.3)$ & $17453(21.8)$ & $16188(17.9)$ & $26826(23.2)$ \\
\hline Treated hypertension & $78323(39.2)$ & $85634(33.6)$ & $24451(39.2)$ & $26721(33.4)$ & $31477(34.9)$ & $32465(28.0)$ \\
\hline Peripheral vascular disease & $5242(2.6)$ & $10380(4.1)$ & $1692(2.7)$ & $3257(4.1)$ & $2846(3.2)$ & $5344(4.6)$ \\
\hline Chronic renal disease & $2325(1.2)$ & $2857(1.1)$ & $718(1.2)$ & $905(1.1)$ & $930(1.0)$ & $1185(1.0)$ \\
\hline Rheumatoid arthritis & $7458(3.7)$ & $4651(1.8)$ & $2204(3.5)$ & $1477(1.8)$ & $1976(2.2)$ & $1206(1.0)$ \\
\hline $\begin{array}{l}\text { Proliferative retinopathy or } \\
\text { maculopathy }\end{array}$ & $5531(2.8)$ & $7657(3.0)$ & $1653(2.6)$ & $2162(2.7)$ & $1319(1.5)$ & $1913(1.7)$ \\
\hline Existing blindness & $3416(1.7)$ & $3701(1.5)$ & $1126(1.8)$ & $1169(1.5)$ & $1789(2.0)$ & $1656(1.4)$ \\
\hline Existing lower limb amputation & $1010(0.5)$ & $2073(0.8)$ & $346(0.6)$ & $728(0.9)$ & $455(0.5)$ & $1013(0.9)$ \\
\hline \multicolumn{7}{|l|}{ Clinical values at baseline: } \\
\hline $\mathrm{HbA}_{1 \mathrm{c}}$ recorded & $141005(70.6)$ & $180594(70.9)$ & $43575(69.8)$ & $56107(70.1)$ & $51725(57.3)$ & $67013(57.9)$ \\
\hline Mean (SD) $\mathrm{HbA}_{1 c}, \mathrm{mmol} / \mathrm{mol}$ & $61.4(20.8)$ & $63(22.0)$ & $61.1(20.8)$ & $62.9(21.9)$ & $60.8(21.1)$ & $62.6(22.0)$ \\
\hline Body mass index recorded & $179818(90.1)$ & $232298(91.1)$ & $55892(89.6)$ & $72979(91.2)$ & $82814(91.7)$ & $107778(93.1)$ \\
\hline Mean (SD) body mass index & $31.1(6.3)$ & $29.8(5.3)$ & $31.2(6.4)$ & $29.9(5.3)$ & $30.9(6.3)$ & $29.7(5.3)$ \\
\hline Cholesterol ratio recorded & $105436(52.8)$ & $138385(54.3)$ & $33392(53.5)$ & $43988(55.0)$ & $35174(39.0)$ & $46530(40.2)$ \\
\hline $\begin{array}{l}\text { Mean (SD) cholesterol/high density } \\
\text { lipoprotein cholesterol ratio }\end{array}$ & $4.1(1.4)$ & $4.5(1.5)$ & $4.1(1.4)$ & $4.5(1.5)$ & $4.2(1.5)$ & $4.5(1.6)$ \\
\hline Systolic blood pressure recorded & $194001(97.2)$ & 246991 (96.9) & $60728(97.3)$ & $77707(97.1)$ & $88792(98.4)$ & $113582(98.1)$ \\
\hline $\begin{array}{l}\text { Mean (SD) systolic blood } \\
\text { pressure, } \mathrm{mm} \mathrm{Hg}\end{array}$ & $139.3(20.0)$ & $138.4(18.6)$ & $139.8(20.0)$ & $138.6(18.6)$ & $141.4(20.6)$ & $140(19.0)$ \\
\hline
\end{tabular}

were assigned to the validation cohort. We identified 455551 patients aged 25-84 years with diabetes in the derivation cohort. We excluded $976(0.21 \%)$ patients without a recorded Townsend deprivation score, leaving 454575 for the derivation analysis. We identified 142718 patients aged 25-84 years with diabetes in the QResearch validation cohort. We excluded $299(0.21 \%)$ patients without a recorded Townsend deprivation score, leaving 142419 for validation analysis. We identified 206050 patients aged 25-84 years with diabetes in the CPRD validation cohort from the 357 practices with linked Townsend scores and hospital admissions and mortality data.

\section{Baseline characteristics}

Table 1 shows baseline characteristics of 454575 patients with diabetes in the derivation cohort at 


\begin{tabular}{|c|c|c|c|c|c|c|}
\hline & $\begin{array}{l}\text { QRese } \\
\text { cohort }\end{array}$ & arch derivation & $\begin{array}{l}\text { QRese } \\
\text { cohort }\end{array}$ & arch validation & CPRD v & alidation cohort \\
\hline & Cases & $\begin{array}{l}\text { Ratet per } 1000 \\
\text { person years } \\
(95 \% \mathrm{CI})\end{array}$ & Cases & $\begin{array}{l}\text { Ratet per } 1000 \\
\text { person years } \\
(95 \% \mathrm{Cl})\end{array}$ & Cases & $\begin{array}{l}\text { Ratet per } 1000 \\
\text { person years } \\
(95 \% \mathrm{Cl})\end{array}$ \\
\hline \multicolumn{7}{|l|}{ Women } \\
\hline Amputation & 1541 & $1.34(1.27$ to 1.41$)$ & 482 & $1.32(1.20$ to 1.44$)$ & 675 & $1.32(1.22$ to 1.42$)$ \\
\hline Blindness & 4074 & 3.43 (3.33 to 3.54$)$ & 1365 & 3.59 (3.40 to 3.79$)$ & 1487 & 2.78 (2.64 to 2.93$)$ \\
\hline \multicolumn{7}{|l|}{ Men } \\
\hline Amputation & 3281 & $2.36(2.28$ to 2.44$)$ & 1042 & 2.33 (2.19 to 2.47$)$ & 1619 & 2.66 (2.53 to 2.79$)$ \\
\hline Blindness & 3989 & 3.03 (2.93 to 3.12) & 1286 & 3.04 (2.88 to 3.21) & 1358 & 2.33 (2.20 to 2.45$)$ \\
\hline
\end{tabular}

study entry. Of these, 94\% had type 2 diabetes. Just over half had been diagnosed as having diabetes less than a year before cohort entry, $17 \%$ had been diagnosed for 1-3 years, 9\% for 4-6 years, $8 \%$ for 7-10 years, and $12 \%$ for 11 or more years. Smoking status was recorded in $95 \%$ of patients, ethnicity in $75 \%$, body mass index in 90\%, systolic blood pressure in $97 \%$, $\mathrm{HbA}_{1 \mathrm{c}}$ in $71 \%$, and cholesterol/high density lipoprotein cholesterol ratio in $53 \%$. Of the 454575 patients in the derivation cohort, 266142 (58.6\%) had missing data for at least one of these variables (including ethnicity).

Baseline characteristics for patients in the QResearch validation cohort were similar to corresponding values in the derivation cohort (table 1). Of the 142419 patients in the QResearch validation cohort, 83403 (58.6\%) had missing data for at least one variable. Baseline characteristics of the CPRD validation cohort were also similar, except that the recording of ethnicity (45\%), cholesterol/high density lipoprotein cholesterol ratio (40\%), and $\mathrm{HbA}_{1 \mathrm{c}}(58 \%)$ was substantially lower in CPRD than in QResearch. Of the 206050 patients in the CPRD validation cohort, 166648 (80.9\%) had missing data for at least one variable.

\section{Primary outcomes of amputation and blindness}

Table 2 shows the number of incident cases of each outcome during follow-up and the age standardised incidence rates in each cohort. In the QResearch derivation cohort, 4822 cases of amputation and 8063 cases of blindness occurred. In addition, 1524 cases of amputation and 2651 cases of blindness occurred in the QResearch validation cohort, and 2294 cases of amputation and 2845 cases of blindness occurred in the CPRD validation cohort. The rate of blindness was lower in men in CPRD (2.33 per 1000 person years) than in both QResearch cohorts (3.03 per 1000 person years) and was also lower in women in CPRD, but rates of amputation were similar.

\section{Predictor variables}

Table 3 shows the adjusted hazard ratios for variables in the final models for men and women in the derivation cohort.

\section{Lower limb amputation}

The final model for lower limb amputation in women included age, systolic blood pressure, $\mathrm{HbA}_{1 \mathrm{c}}$, deprivation, duration of diabetes, smoking status, ethnicity, rheumatoid arthritis, congestive cardiac failure, peripheral vascular disease, and chronic renal disease. The final model in men also included type of diabetes and atrial fibrillation. Body mass index and the serum cholesterol/high density lipoprotein cholesterol ratio were not significantly associated with risk in men or women. Increasing duration of diabetes was associated with an increased risk of lower limb amputation in men and women. Increasing levels of smoking were associated with an increased risk of amputation; the association was more marked in women than in men. For heavy smokers compared with non-smokers, a 1.9-fold increase in risk of amputation was seen for women and a 1.3-fold increased risk for men. South Asian ethnic groups had a lower risk compared with people whose ethnic group was either white or not recorded; Caribbean and black African men also had lower risks. Pre-existing peripheral vascular disease was associated with the highest risks (fourfold in women and threefold in men), followed by chronic renal disease (2.7-fold in women and 2.3-fold in men).

Figs 1-3 show adjusted hazard ratios for age, $\mathrm{HbA}_{1 \mathrm{c}}$, and systolic blood pressure. Increasing values of age, $\mathrm{HbA}_{1 \mathrm{c}}$, and systolic blood pressure, were associated with an increased risk of lower limb amputation in men and women.

\section{Blindness}

The final models for blindness in men and women included age, cholesterol/high density lipoprotein cholesterol ratio, systolic blood pressure, $\mathrm{HbA}_{1 \mathrm{c}}$, deprivation, duration of diabetes, type of diabetes, chronic renal disease, and existing proliferative retinopathy or maculopathy. Body mass index and smoking status were not significantly associated with risk. Increasing values of age, $\mathrm{HbA}_{1 \mathrm{c}}$, and systolic blood pressure were associated with an increased risk of blindness (figs 1-3). Increasing values of the serum cholesterol/high density lipoprotein cholesterol ratio were also associated with an increased risk of blindness. Increasing duration of diabetes was associated with increased risk despite adjustment for age and other risk factors. We found a significant interaction between renal disease and age. Pre-existing proliferative retinopathy or maculopathy was the strongest risk factor, with a 2.7-fold increase for women and a 2.9-fold increase for men.

\section{Web calculator}

The web calculator that implements the risk equations for the final models can be found at qdiabetes.org/ amputation-blindness/index.php, along with the open source software which includes the equations (published separately, as these will be updated over time as newer data becomes available). 


\begin{tabular}{|c|c|c|}
\hline \multirow[b]{2}{*}{ Characteristic } & \multicolumn{2}{|c|}{ Adjusted hazard ratio $(95 \% \mathrm{Cl})$} \\
\hline & Women & Men \\
\hline \multicolumn{3}{|l|}{ Amputation* } \\
\hline Townsend deprivation scoret & $1.10(1.01$ to 1.19$)$ & $1.29(1.22$ to 1.36$)$ \\
\hline \multicolumn{3}{|l|}{ Duration of diabetes: } \\
\hline Newly diagnosed ( $<1$ year) & 1 & 1 \\
\hline $1-3$ years & $1.59(1.36$ to 1.85$)$ & $1.68(1.51$ to 1.87$)$ \\
\hline 4-6 years & $1.69(1.42$ to 2.01$)$ & $2.03(1.81$ to 2.28$)$ \\
\hline $7-10$ years & $2.37(2.01$ to 2.79$)$ & $2.67(2.39$ to 3.00$)$ \\
\hline$>10$ years & $3.30(2.89$ to 3.78$)$ & $3.49(3.15$ to 3.86$)$ \\
\hline \multicolumn{3}{|l|}{ Smoking status: } \\
\hline Non-smoker & 1 & 1 \\
\hline Ex-smoker & $1.08(0.94$ to 1.24$)$ & $0.94(0.87$ to 1.03$)$ \\
\hline Light smoker & $1.59(1.34$ to 1.88$)$ & $1.28(1.14$ to 1.43$)$ \\
\hline Moderate smoker & $1.58(1.25$ to 1.99$)$ & $1.15(0.96$ to 1.37$)$ \\
\hline Heavy smoker & $1.89(1.49$ to 2.41$)$ & $1.26(1.06$ to 1.49$)$ \\
\hline \multicolumn{3}{|l|}{ Ethnicity: } \\
\hline White/not recorded & 1 & 1 \\
\hline Indian & $0.44(0.28$ to 0.68$)$ & $0.42(0.32$ to 0.55$)$ \\
\hline Pakistani & $0.72(0.47$ to 1.12$)$ & $0.40(0.28$ to 0.58$)$ \\
\hline Bangladeshi & $0.29(0.15$ to 0.56$)$ & $0.12(0.07$ to 0.22$)$ \\
\hline Other Asian & $0.70(0.39$ to 1.27$)$ & $0.42(0.26$ to 0.67$)$ \\
\hline Caribbean & $0.87(0.65$ to 1.18$)$ & $0.49(0.36$ to 0.66$)$ \\
\hline Black African & $0.92(0.55$ to 1.54$)$ & $0.38(0.23$ to 0.61$)$ \\
\hline Chinese & $0.50(0.12$ to 1.99$)$ & $0.35(0.11$ to 1.09$)$ \\
\hline Other & $0.70(0.44$ to 1.10$)$ & $0.63(0.45$ to 0.87$)$ \\
\hline \multicolumn{3}{|l|}{ Comorbidity: } \\
\hline Type 1 diabetes (versus type 2) & NS & $1.26(1.09$ to 1.45$)$ \\
\hline Rheumatoid arthritis & $1.50(1.19$ to 1.90$)$ & $1.39(1.11$ to 1.75$)$ \\
\hline Atrial fibrillation & NS & $1.26(1.07$ to 1.49$)$ \\
\hline Congestive cardiac failure & $1.79(1.44$ to 2.22$)$ & $1.34(1.14$ to 1.58$)$ \\
\hline Peripheral vascular disease & $4.26(3.63$ to 4.99$)$ & $3.16(2.84$ to 3.51$)$ \\
\hline Chronic renal disease & $2.68(1.96$ to 3.66$)$ & $2.26(1.80$ to 2.85$)$ \\
\hline \multicolumn{3}{|l|}{ Blindness $¥$} \\
\hline Cholesterol/HDL ratioß & $1.06(1.03$ to 1.09$)$ & $1.03(1.00$ to 1.06$)$ \\
\hline Townsend deprivation scoret & $1.21(1.15$ to 1.27$)$ & $1.33(1.27$ to 1.39$)$ \\
\hline \multicolumn{3}{|l|}{ Duration of diabetes: } \\
\hline Newly diagnosed ( $<1$ year) & 1 & 1 \\
\hline $1-3$ years & $1.36(1.25$ to 1.49$)$ & $1.40(1.28$ to 1.54$)$ \\
\hline 4-6 years & $1.51(1.36$ to 1.67$)$ & $1.42(1.28$ to 1.58$)$ \\
\hline $7-10$ years & $1.72(1.55$ to 1.91$)$ & $1.57(1.41$ to 1.76$)$ \\
\hline$>10$ years & $2.17(1.97$ to 2.38$)$ & 2.09 (1.90 to 2.29$)$ \\
\hline \multicolumn{3}{|l|}{ Comorbidity: } \\
\hline Type 1 diabetes (versus type 2) & $1.50(1.26$ to 1.78$)$ & $1.44(1.22$ to 1.70$)$ \\
\hline Chronic renal disease & $1.49(1.17$ to 1.89$)$ & 2.57 (1.88 to 3.52$)$ \\
\hline Proliferative retinopathy/maculopathy & $2.67(2.37$ to 3.02$)$ & $2.93(2.61$ to 3.29$)$ \\
\hline
\end{tabular}
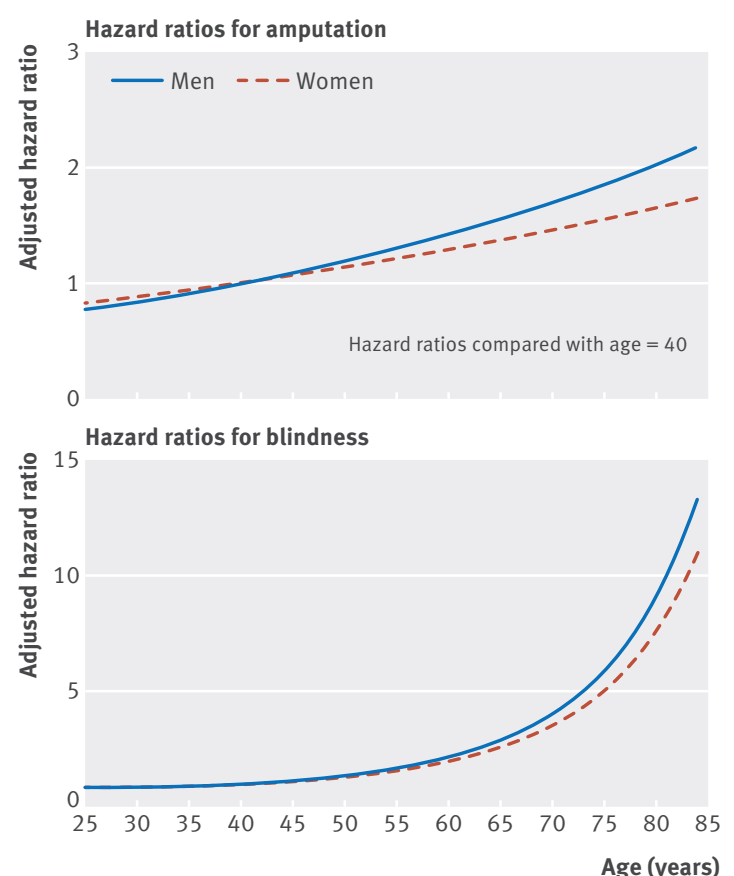

Fig 1 Adjusted hazard ratios for blindness and lower limb amputation by age in derivation cohort

discrimination was good for amputation (D statistic 1.69, Harrell's C statistic 0.77) and blindness (D statistic 1.40, Harrell's C statistic 0.73). The results for women in the CPRD cohort were very similar to those for men. The results for both sexes in the CPRD cohort were similar to those for the QResearch validation cohort, although the point estimates for CPRD tended to be marginally higher.
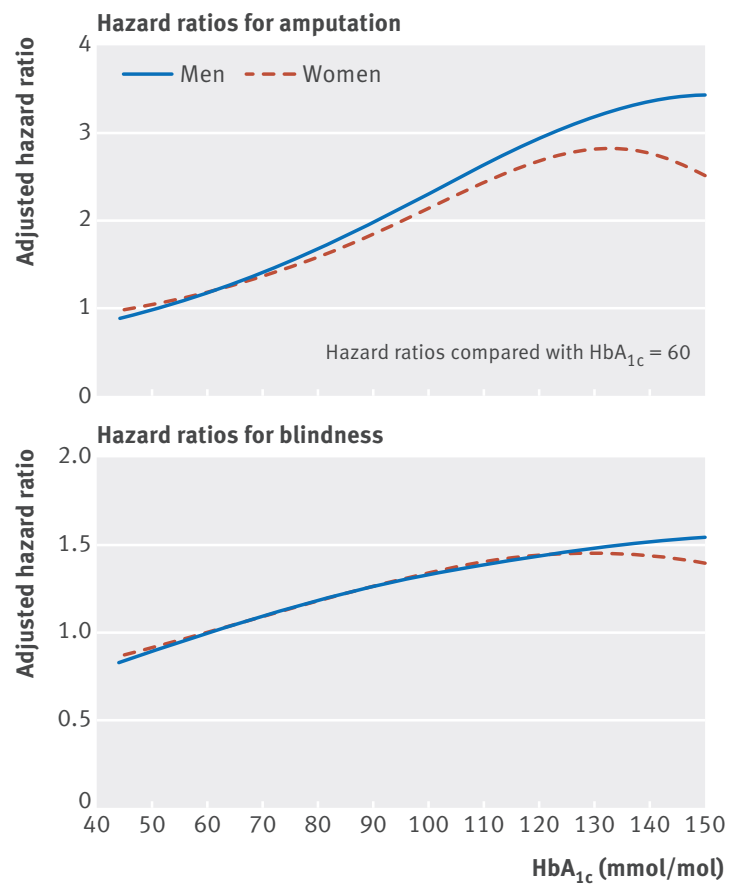

Fig 2 | Adjusted hazard ratios for blindness and lower limb amputation by $\mathrm{HbA}_{1 \mathrm{c}}$ in derivation cohort

\section{Validation \\ iscrimination}

Table 4 shows the performance of each equation in both validation cohorts. For men in the CPRD cohort, the equations explained $40.6 \%$ of the variation in time to diagnosis of amputation and 31.9\% for blindness, and

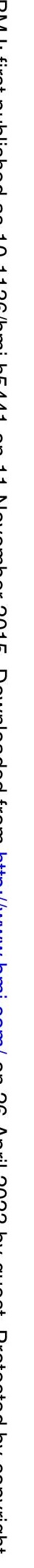



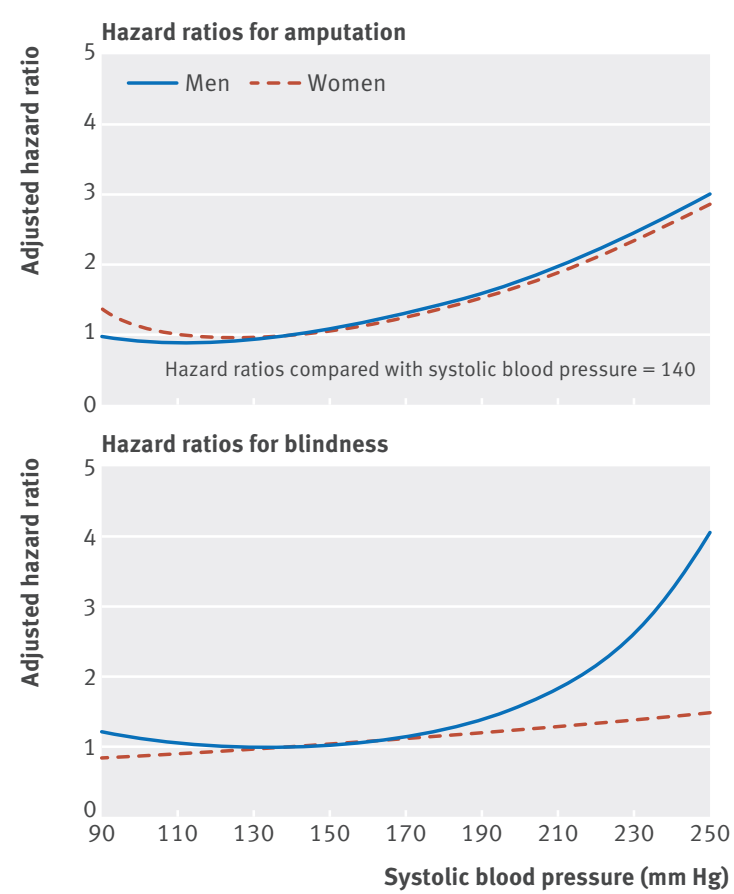

Fig 3 Adjusted hazard ratios for blindness and lower limb amputation by systolic blood pressure in derivation cohort

\section{Calibration}

Figure 4 shows the mean predicted and observed risks of both outcomes at 10 years by 10th of predicted risk, applying the equations to men and women in the QResearch validation cohort. Figure 5 shows comparable results for the CPRD cohort. We found close correspondence between the mean predicted risks and the observed risks within each model 10th, indicating that

\begin{tabular}{|c|c|c|}
\hline \multirow[b]{2}{*}{ Statistic } & \multicolumn{2}{|l|}{ Mean $(95 \% \mathrm{Cl})$} \\
\hline & CPRD validation cohort & $\begin{array}{l}\text { QResearch validation } \\
\text { cohort }\end{array}$ \\
\hline \multicolumn{3}{|l|}{ Women } \\
\hline \multicolumn{3}{|l|}{ Amputation: } \\
\hline D statistic ${ }^{\star}$ & 1.61 (1.45 to 1.77$)$ & 1.30 (1.14 to 1.47$)$ \\
\hline$R^{2}(\%) \dagger$ & $38.22(33.61$ to 42.83$)$ & $28.90(23.70$ to 34.10$)$ \\
\hline Harrell’s C statistic $\neq$ & 0.762 (0.735 to 0.789 ) & 0.700 (0.670 to 0.731$)$ \\
\hline \multicolumn{3}{|l|}{ Blindness: } \\
\hline D statistic ${ }^{\star}$ & $1.36(1.27$ to 1.46$)$ & $1.32(1.23$ to 1.42$)$ \\
\hline$R^{2}(\%) \dagger$ & 30.78 (27.94 to 33.63$)$ & 29.44 (26.50 to 32.39$)$ \\
\hline Harrell’s C statistic & 0.733 (0.719 to 0.747$)$ & 0.725 (0.709 to 0.741$)$ \\
\hline \multicolumn{3}{|l|}{ Men } \\
\hline \multicolumn{3}{|l|}{ Amputation: } \\
\hline D statistic* & $1.69(1.59$ to 1.79$)$ & $1.48(1.38$ to 1.59$)$ \\
\hline$R^{2}(\%) \dagger$ & $40.57(37.70$ to 43.44$)$ & $34.42(31.14$ to 37.70$)$ \\
\hline Harrell’s C statistic & 0.770 (0.755 to 0.784$)$ & 0.748 (0.730 to 0.767$)$ \\
\hline \multicolumn{3}{|l|}{ Blindness: } \\
\hline D statistic ${ }^{\star}$ & $1.40(1.31$ to 1.49$)$ & $1.33(1.23$ to 1.42$)$ \\
\hline$R^{2}(\%) \dagger$ & 31.93 (29.04 to 34.82 ) & 29.57 (26.53 to 32.62 ) \\
\hline Harrell’s C statistic & 0.732 (0.716 to 0.747$)$ & 0.714 (0.696 to 0.731$)$ \\
\hline \multicolumn{3}{|c|}{$\begin{array}{l}\text { *A measure of discrimination that is specific to censored survival data for which higher values indicate better } \\
\text { discrimination. } \\
\text { tMeasures explained variation in time to diagnosis of outcome; higher values indicate that more variation is } \\
\text { explained. }\end{array}$} \\
\hline
\end{tabular}

the equations were well calibrated across both validation cohorts.

\section{Performance at threshold for $10 \%$ and $20 \%$ of patients at highest risk}

Table 5 shows the sensitivity, specificity, and observed risk for the $10 \%$ and $20 \%$ of men and women at the highest predicted risk of each outcome for both validation cohorts for illustrative purposes. For example, when we used a 10 year risk threshold of 3.2\% for amputation in men in CPRD to identify the $20 \%$ at highest predicted risk, the sensitivity was $58 \%$, the specificity was $80.5 \%$, and the observed risk was $7 \%$.

\section{Implementation}

Figure 6 shows a clinical example of the implementation of the equations using the web calculator (qdiabetes. org/amputation-blindness/index.php). The example is for a 50 year old female non-smoker with newly diagnosed type 2 diabetes and an $\mathrm{HbA}_{1 \mathrm{c}}$ of $65 \mathrm{mmol} / \mathrm{mol}$, a cholesterol/high density lipoprotein cholesterol ratio of 2, and a systolic blood pressure of $140 \mathrm{~mm} \mathrm{Hg}$. Her 10 year risk of blindness is $1 \%$, and her risk of amputation is $0.5 \%$.

Figure 7 shows the results for a 75 year old man, diagnosed as having type 2 diabetes 10 years ago, who is a moderate smoker and has chronic kidney disease, an $\mathrm{HbA}_{1 \mathrm{c}}$ of $70 \mathrm{mmol} / \mathrm{mol}$, a cholesterol/high density lipoprotein cholesterol ratio of 4 , and a systolic blood pressure of $160 \mathrm{~mm} \mathrm{Hg}$. His 10 year risk of blindness is $14.7 \%$, and his risk of amputation is $12.1 \%$.

\section{Discussion}

We have developed and externally validated risk prediction equations to quantify the absolute risks of blindness and lower limb amputation over 10 years in men and women with type 1 and type 2 diabetes. The equations are well calibrated and have good discrimination, with $C$ statistic values of at least 0.73 in the external CPRD validation cohort. To our knowledge, these are the first tools for predicting the 10 year risk of both blindness and amputation, two of the complications that most concern patients with diabetes and affect quality of life.

\section{Clinical implications}

These algorithms are designed to provide better information for patients and doctors on the absolute risks of blindness and amputation, to inform management decisions. Patients with diabetes tend to overestimate their risk of complications and also overestimate the benefits of treatment. ${ }^{10}$ For example, in one study, patients believed that they were 1.5 times more likely to become blind and 13 times more likely to have a lower leg amputation than estimates of absolute risk based on the DCCT trial. ${ }^{210}$ Some people may argue that overestimating the risk of complications might result in patients being more likely to take intensive treatment. However, from a holistic and ethical point of view, more accurate individualised information on the risk of complications 

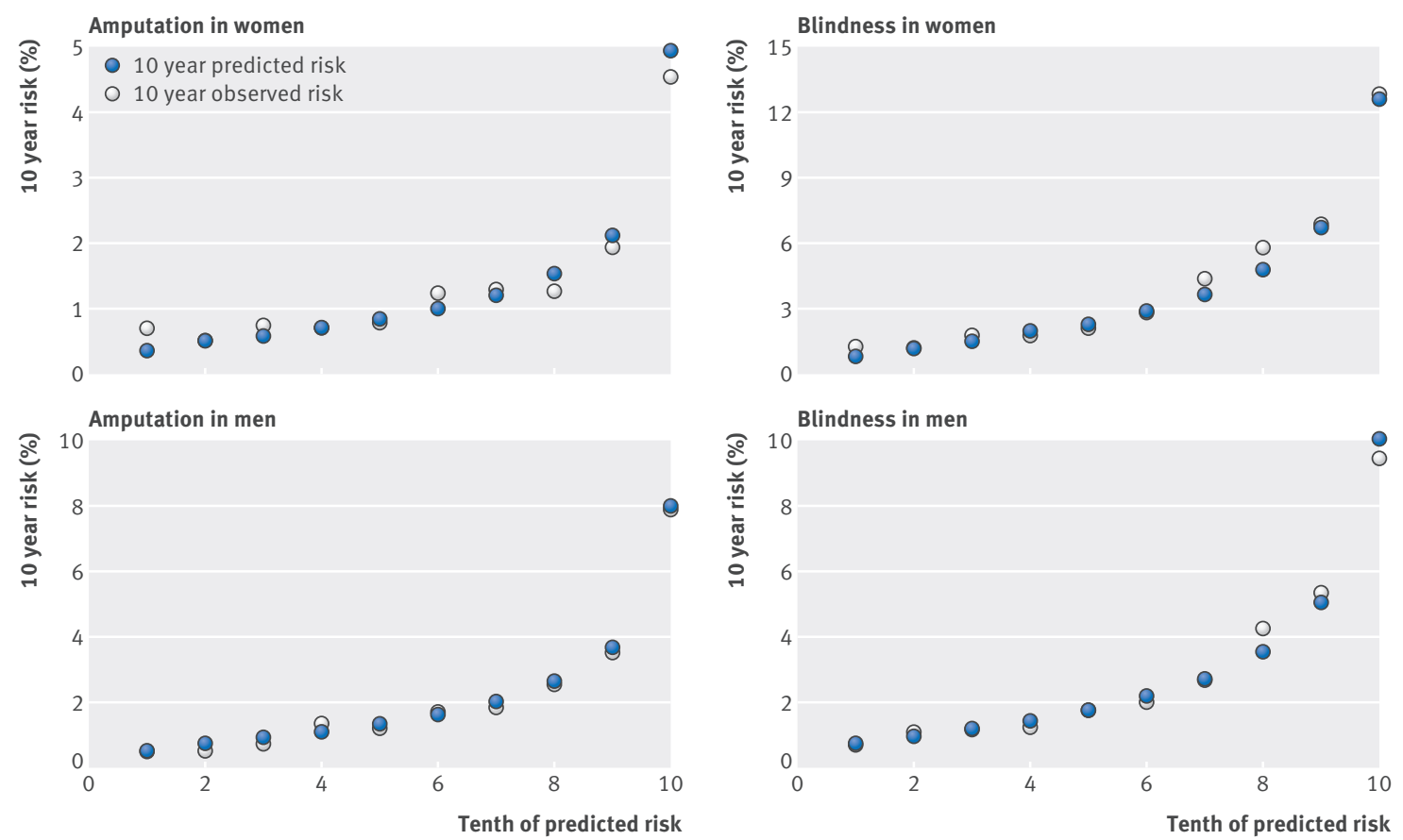

Fig 4 Mean predicted risks and observed risks of blindness and lower limb amputation at 10 years by 10 th of predicted risk, applying equations to all men and women in QResearch validation cohort

may help patients to make more informed decisions about the balance of risks and benefits of treatment options reflecting their own values and choices. Overestimation of the risk of complications might lead to increased levels of anxiety and depression, which could negatively affect quality of life. This is especially important as patients with diabetes are more likely than the general population to experience anxiety and depression. ${ }^{38}$

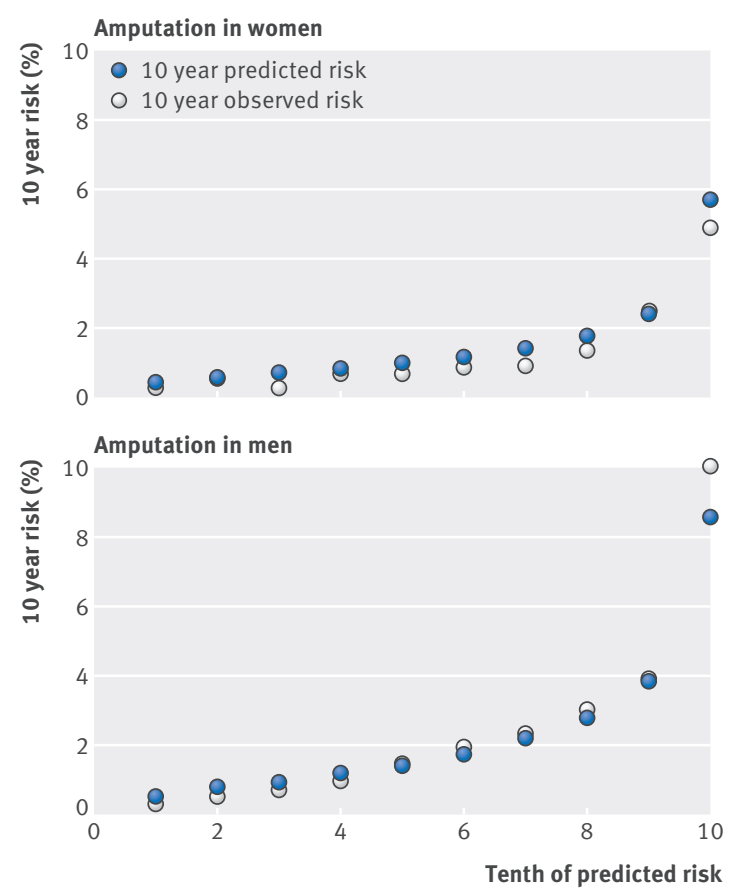

For clinicians and the health service, more accurate methods for stratifying patients according to their absolute risk of complications could enable screening programmes to be tailored to an individual's level of risk and support the more rational use of scarce resources. For example, blindness can be prevented by screening for and treatment of retinopathy, ${ }^{39}$ and patients at high risk of blindness might need retinal screening more often than once a year. Those at higher
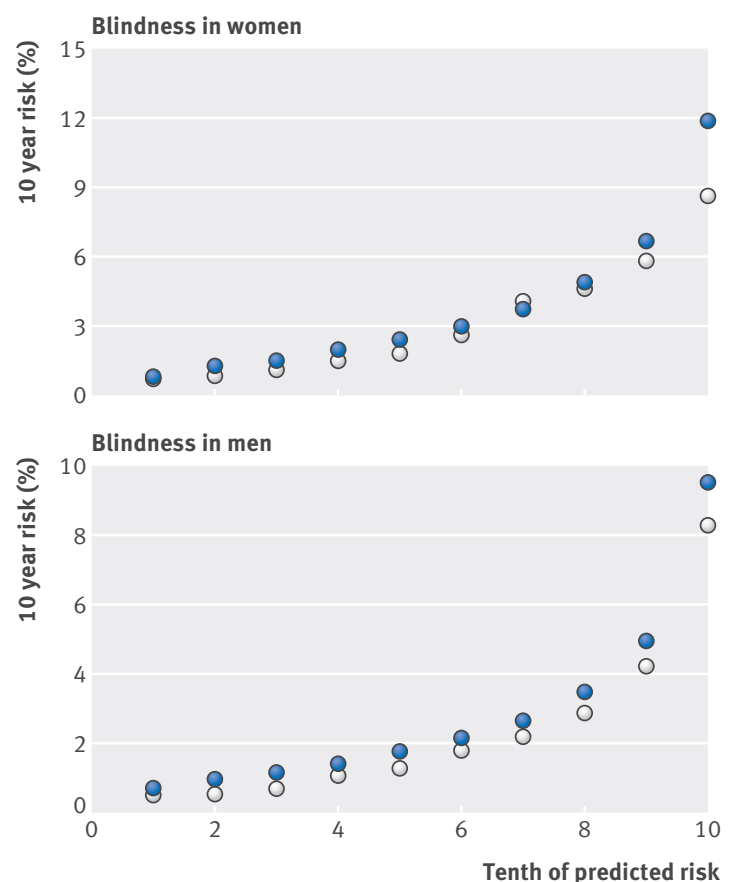

Fig 5 Mean predicted risks and observed risks of blindness and lower limb amputation at 10 years by 10 th of predicted risk, applying equations to all men and women in CPRD validation cohort 


\begin{tabular}{|c|c|c|c|c|c|c|c|c|}
\hline & \multicolumn{4}{|c|}{ QResearch cohort } & \multicolumn{4}{|l|}{ CPRD cohort } \\
\hline & $\begin{array}{l}\text { Cut-off (\%) for } \\
10 \text { year risk* }\end{array}$ & Sensitivity (\%) & Specificity (\%) & $\begin{array}{l}\text { Observed } \\
\text { risk (\%) }\end{array}$ & $\begin{array}{l}\text { Cut-off (\%) for } \\
10 \text { year risk* }\end{array}$ & Sensitivity (\%) & Specificity (\%) & Observed risk (\%) \\
\hline \multicolumn{9}{|l|}{ Women } \\
\hline Amputation (top 10\%) & 2.6 & 33.2 & 90.2 & 4.6 & 2.9 & 39.4 & 90.2 & 4.9 \\
\hline Amputation (top 20\%) & 1.8 & 48.1 & 80.2 & 3.2 & 2.0 & 59.8 & 80.3 & 3.7 \\
\hline Blindness (top 10\%) & 8.1 & 27.9 & 90.4 & 12.8 & 8.0 & 25.7 & 90.2 & 8.7 \\
\hline Blindness (top 20\%) & 5.6 & 45.1 & 80.5 & 9.6 & 5.6 & 44.3 & 80.4 & 7.2 \\
\hline \multicolumn{9}{|l|}{ Men } \\
\hline Amputation (top 10\%) & 4.5 & 37.5 & 90.3 & 7.9 & 4.8 & 41.9 & 90.4 & 10.2 \\
\hline Amputation (top 20\%) & 3.0 & 53.5 & 80.4 & 5.7 & 3.2 & 58.0 & 80.5 & 7.0 \\
\hline Blindness (top 10\%) & 6.2 & 27.6 & 90.2 & 9.5 & 6.0 & 31.5 & 90.2 & 8.3 \\
\hline Blindness (top 20\%) & 4.1 & 45.9 & 80.4 & 7.2 & 4.1 & 49.1 & 80.3 & 6.1 \\
\hline
\end{tabular}

*Risk threshold for $10 \%$ or $20 \%$ of patients at highest predicted risk of outcome over 10 years.

risk of amputation might benefit from a proactive targeted programme to prevent lower extremity amputation (including more frequent checks, tailored patient education, specially designed protective footwear, and early reporting of foot injuries), as this has been shown to substantially reduce the risk of emergency admissions, use of antibiotics, foot operations, and lower limb amputation compared with usual practice. ${ }^{40} 41$ Better information on the absolute risk of individual complications could also prompt more intensive treatment of modifiable risk factors-such as lowering of $\mathrm{HbA}_{1 \mathrm{c}}$ and tighter blood pressure control-which are generally considered to reduce the risk of microvascular complications such as blindness. ${ }^{2542}$

\section{Comparisons with literature}

The incidence rates of amputation and blindness are comparable to the amputation rate of 1.6 per 1000 patient years and blindness rate of 3.5 per 1000 patient years reported by the UKPDS. ${ }^{5}$ However, our study is approximately 100-fold larger than the UKPDS, with almost 5000 incident amputations and more than 8000 cases of recorded blindness in the derivation cohort, and it is 10 times larger than the US hospital based

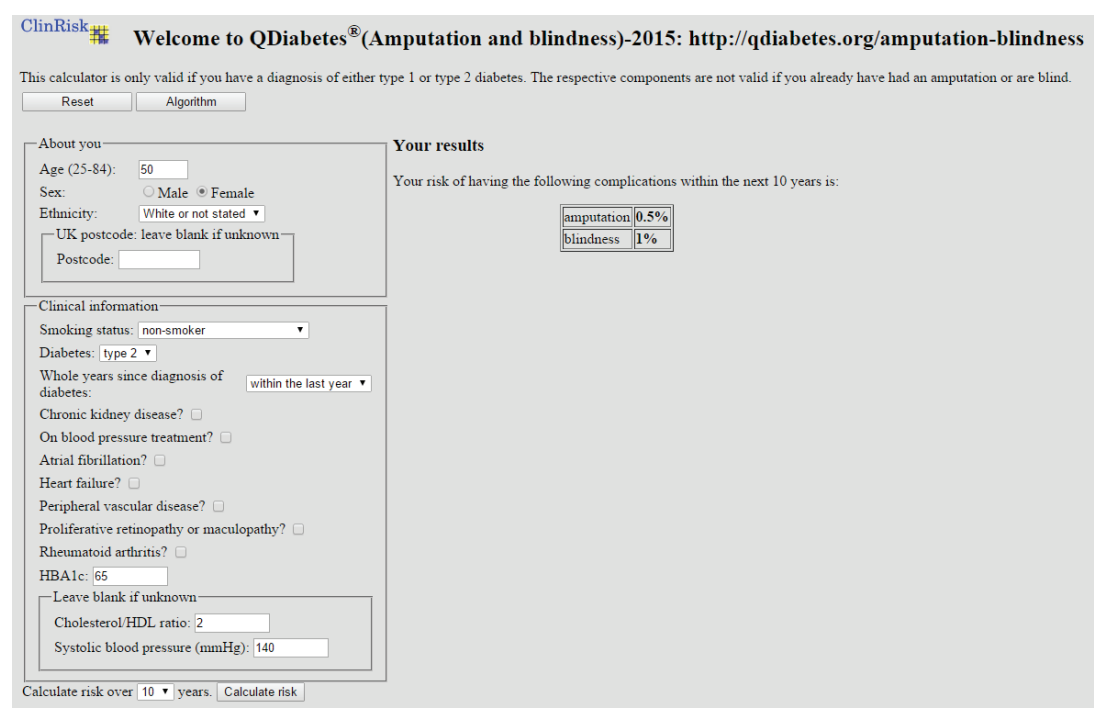

Fig 6 | Web calculator applied to example female patient cohort study reported by Zhao et al. ${ }^{24}$ Our study is also more recent than the UKPDS, which started almost 40 years ago and ended almost 20 years ago. ${ }^{5}$ Our study included patients with prevalent type 1 and type 2 diabetes as well as those with a new diagnosis, enabling us to account for the important contribution of duration of diabetes to risk and to ensure that the results can be applied to patients with either newly diagnosed or prevalent diabetes.

We included established risk factors in our equations and report hazard ratios similar in both magnitude and direction to those reported elsewhere for lower limb amputation, ${ }^{1}$ progression of retinopathy, and blindness, ${ }^{120}$ which increases the clinical face validity of the equations. As in the UKPDS, ${ }^{6}$ increased systolic blood pressure was associated with increased risks of blindness and lower limb amputation, ${ }^{20}$ and increased levels of $\mathrm{HbA}_{1 \mathrm{c}}$ were associated with increased risks of blindness and amputation when compared over equivalent ranges. ${ }^{124}$ Deprivation and smoking were associated with an increased risk of amputation in our study and others. ${ }^{21}$ However, smoking was not associated with an increased risk of blindness in our study, which is consistent with other research. ${ }^{20}$ Non-white ethnic groups had lower risks of lower limb amputation compared with the white group. This contrasts with a US study in which black Africans had a higher risk of amputation. ${ }^{19}$

Three economic models have been based on the DCCT and UKPDS studies. ${ }^{2} 5$ The CORE diabetes and Sheffield diabetes models are based on equations derived from the DCCT trial and the UKPDS study. ${ }^{43-45}$ The EAGLE model is based on equations derived from UKPDS and the DCCT, as well as the Wisconsin Epidemiological Study of Diabetic Retinopathy. ${ }^{46}$ The CORE model predicts risk of amputation, ${ }^{46}$ and the CORE, EAGLE, and Sheffield models predict retinopathy rather than blindness.

\section{Methodological considerations}

The methods used to derive and validate these models are very similar to those for other risk prediction tools derived from the QResearch database, the strengths and limitations of which have been discussed in detail. ${ }^{112}$ In summary, key strengths include cohort size, duration 


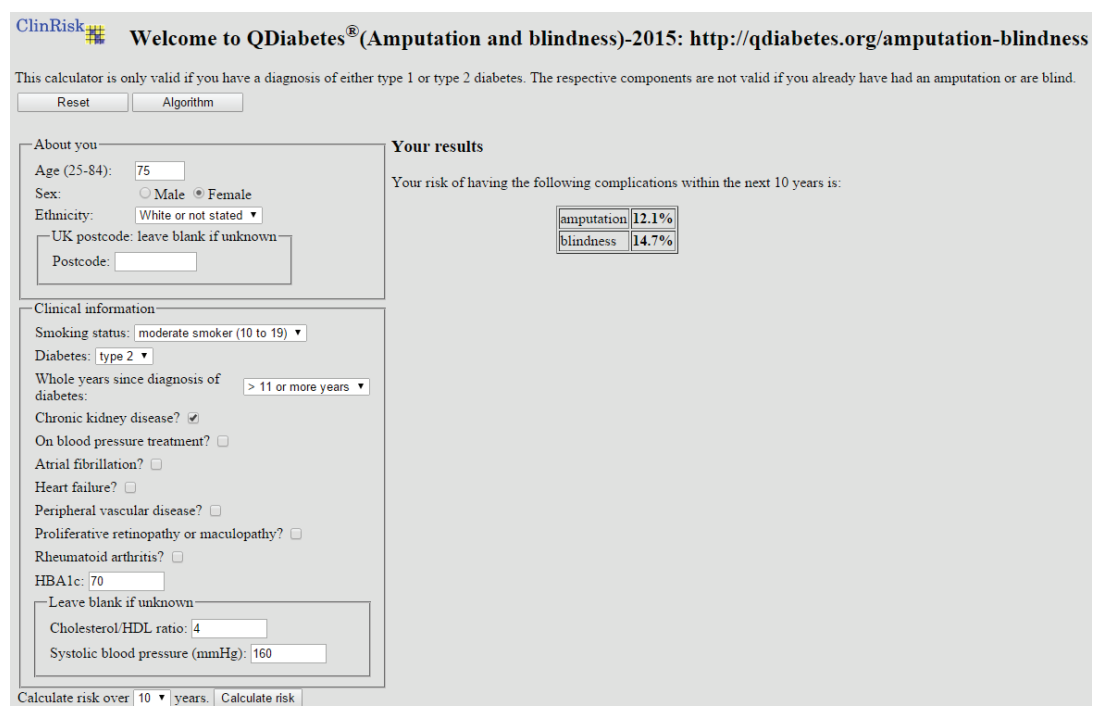

Fig $7 \mid$ Web calculator applied to example male patient

\section{Conclusion}

We have developed and validated new risk prediction equations to quantify the absolute risks of blindness and lower limb amputation in patients with diabetes. They can be used to identify patients with diabetes at high risk of these complications for further assessment. Further research is needed to evaluate the clinical outcomes and cost effectiveness of using these risk equations in primary care.

We acknowledge the contribution of EMIS practices who contribute to the QResearch and EMIS for expertise in establishing, developing, and supporting the database.

Contributors: $\mathrm{JH}-\mathrm{C}$ initiated the study; did the literature review, data extraction, data manipulation, and primary data analysis; and wrote the first draft of the paper. CC contributed to the study design, the analysis and interpretation of the data, and the drafting of the paper.

Funding: No external funding.

Competing interests: Both authors have completed the ICMJE uniform disclosure form at www.icmje.org/coi_disclosure.pdf (available on request from the corresponding author) and declare: $\mathrm{JH}-\mathrm{C}$ is co-director of QResearch, a not for profit organisation which is a joint partnership between the University of Nottingham and Egton Medical Information Systems (leading commercial supplier of IT for $60 \%$ of general practices in the UK), and is also a paid director of ClinRisk Ltd, which produces open and closed source software to ensure the reliable and updatable implementation of clinical risk equations within clinical computer systems to help improve patient care; CC is a paid consultant statistician for ClinRisk Ltd. This work and any views expressed within it are solely those of the co-authors and not of any affiliated bodies or organisations.

Ethical approval: The project was reviewed in accordance with the QResearch agreement with NRES Committee East Midlands - Derby (reference 03/4/021). The project was reviewed by the independent scientific committee of the Clinical Research Practice Datalink (reference 13_079).

Data sharing: The equations presented in this paper will be released as open source software under the GNU lesser GPL v3. Open source software allows use without charge under the terms of the GNU lesser public license version 3. Closed source software can be licensed at a fee.

Transparency declaration: The lead author (the manuscript's guarantor) affirms that this manuscript is an honest, accurate, and transparent account of the study being reported; that no important aspects of the study have been omitted; and that any discrepancies from the study as planned (and, if relevant, registered) have been explained.

This is an Open Access article distributed in accordance with the terms of the Creative Commons Attribution (CC BY 4.0) license, which permits others to distribute, remix, adapt and build upon this work, for commercial use, provided the original work is properly cited. See: http://creativecommons.org/licenses/by/4.0/

1 Stratton IM, Adler Al, Neil HA, et al. Association of glycaemia with macrovascular and microvascular complications of type 2 diabetes (UKPDS 35): prospective observational study. BMJ 2000;321:405-12

2 Diabetes Control and Complications Trial Research Group. The effect of intensive treatment of diabetes on the development and progression of long-term complications in insulin-dependent diabetes mellitus. N Engl I Med 1993:329:977-86.

3 Health and Social Care Information Centre. National Diabetes Audit 2012-2013. Report 2: complications and mortality. HSCIC, 2014:37.

DCCT/EDIC Research Group, Aiello LP, Sun W, et al. Intensive diabetes therapy and ocular surgery in type 1 diabetes. N Engl / Med 2015;372:1722-33.

5 UK Prospective Diabetes Study (UKPDS) Group. Intensive bloodglucose control with sulphonylureas or insulin compared with conventional treatment and risk of complications in patients with type 2 diabetes (UKPDS 33). Lancet 1998;352:837-53.

6 Adler Al, Stratton IM, Neil HA, et al. Association of systolic blood pressure with macrovascular and microvascular complications of type 2 diabetes (UKPDS 36): prospective observational study. BMJ 2000;321:412-9.

7 National Clinical Guideline Centre. Lipid modification: cardiovascular risk assessment and the modification of blood lipids for the primary and secondary prevention of cardiovascular disease. National Clinical Guideline Centre, 2014:286.

group, as that would require consideration of the balance of risks and benefits for individuals and cost effectiveness analyses, which are outside the scope of this study. 
8 Goff DC, Lloyd-Jones DM, Bennett G, et al. 2013 ACC/AHA guideline on the assessment of cardiovascular risk: a report of the American College of Cardiology/American Heart Association Task Force on Practice Guidelines. Circulation 2014;129(25 suppl 2):S49-73.

9 Health and Social Care Information Centre. Quality and outcomes framework. 2015. www.ic.nhs.uk/services/qof.

10 Meltzer D, Egleston B. How patients with diabetes perceive their risk for major complications. Eff Clin Pract 2000;3:7-15

11 Hippisley-Cox J, Coupland C, Vinogradova Y, et al. Predicting cardiovascular risk in England and Wales: prospective derivation and validation of QRISK2. BMJ 2008;336:1475-82.

12 Hippisley-CoxJ, Coupland C, Brindle P. Derivation and validation of QStroke score for predicting risk of ischaemic stroke in primary care and comparison with other risk scores: a prospective open cohort study. BMJ 2013;346:f2573

13 Hippisley-Cox J, Coupland C. Predicting the risk of chronic kidney disease in men and women in England and Wales: prospective derivation and external validation of the QKidney(R) Scores. BMC Fam Pract 2010;11:49.

14 Clarke P, Gray A, Holman R. Estimating utility values for health states of type 2 diabetic patients using the EQ-5D (UKPDS 62). Med Decis Making 2002;22:340-9.

15 Wikipedia. Read code. 2015. en.wikipedia.org/wiki/Read code.

16 Hippisley-Cox J, Coupland C, Robson J, et al. Predicting risk of type 2 diabetes in England and Wales: prospective derivation and validation of QDScore. BMJ 2009;338:b880.

17 Hippisley-Cox J, Pringle M. Prevalence, care and outcomes for patients with diet controlled diabetes in general practice: cross sectional survey. Lancet 2004;364:423-8.

18 Health and Social Care Information Centre. OPCS-4 classification. systems.hscic.gov.uk/data/clinicalcoding/codingstandards/opcs4/.

19 Resnick HE, Valsania P, Phillips CL. Diabetes mellitus and nontraumatic lower extremity amputation in black and white Americans: the National Health and Nutrition Examination Survey Epidemiologic Follow-up Study, 1971-1992. Arch Intern Med 1999;159:2470-5.

20 Stratton IM, Kohner EM, Aldington SJ, et al. UKPDS 50: risk factors for incidence and progression of retinopathy in type II diabetes over 6 years from diagnosis. Diabetologia 2001;44:156-63.

21 Leggetter S, Chaturvedi N, Fuller JH, et al. Ethnicity and risk of diabetes-related lower extremity amputation: a population-based, case-control study of African Caribbeans and Europeans in the United Kingdom. Arch Intern Med 2002;162:73-8.

22 Moss SE, Klein R, Klein BE. The 14-year incidence of lower-extremity amputations in a diabetic population: the Wisconsin Epidemiologic Study of Diabetic Retinopathy. Diabetes Care 1999;22:951-9.

23 Klein R. Hyperglycemia and microvascular and macrovascular disease in diabetes. Diabetes Care 1995;18:258-68.

24 Zhao W, Katzmarzyk PT, Horswell R, et al. HbA(1c) and lower-extremity amputation risk in low-income patients with diabetes. Diabetes Care 2013;36:3591-8.

25 Barth JH, Marshall SM, Watson ID. Consensus meeting on reporting glycated haemoglobin (HbA1c) and estimated average glucose (eAG) in the UK: report to the National Director for Diabetes, Department of Health. Diabet Med 2008;25:381-2.

26 Drugs and Therapeutics Bulletin. Change in units for $\mathrm{HbA}_{1 c}$. 2010. dtb. bmj.com/site/about/HBA1C_chart_Feb_10.pdf.

27 Royston P, Ambler G, Sauerbrei W. The use of fractional polynomials to model continuous risk variables in epidemiology. Int J Epidemiol 1999;28:964-74

28 Steyerberg EW, van Veen M. Imputation is beneficial for handling missing data in predictive models. J Epidemiol Community Health 2007;60:979.
29 Moons KG, Donders RA, Stijnen T, et al. Using the outcome for imputation of missing predictor values was preferred. J Epidemiol Community Health 2006;59:1092.

30 Schafer J, Graham J. Missing data: our view of the state of the art. Psychol Methods 2002;7:147-77.

31 White IR, Royston P, Wood AM. Multiple imputation using chained equations: issues and guidance for practice. Stat Med 2011;30:377-99.

32 Rubin DB. Multiple imputation for non-response in surveys. John Wiley, 1987.

33 Hosmer D, Lemeshow S, May S. Applied survival analysis: regression modelling of time to event data. Wiley, 2007.

34 Royston P. Explained variation for survival models. Stata J 2006;6:1-14.

35 Royston P, Sauerbrei W. A new measure of prognostic separation in survival data. Stat Med 2004;23:723-48.

36 Harrell FE Jr, Califf RM, Pryor DB, et al. Evaluating the yield of medical tests. JAMA 1982;247:2543-6.

37 Collins GS, Reitsma JB, Altman DG, et al. Transparent Reporting of a multivariable prediction model for Individual Prognosis Or Diagnosis (TRIPOD): the TRIPOD statement. Ann Intern Med 2015;162:55-63.

38 Gavard JA, Lustman PJ, Clouse RE. Prevalence of depression in adults with diabetes: an epidemiological evaluation. Diabetes Care 1993;16:1167-78.

39 Bachmann MO, Nelson SJ. Impact of diabetic retinopathy screening on a British district population: case detection and blindness prevention in an evidence-based model. J Epidemiol Community Health 1998;52:45-52.

40 Patout CA Jr, Birke JA, Horswell R, et al. Effectiveness of a comprehensive diabetes lower-extremity amputation prevention program in a predominantly low-income African-American population. Diabetes Care 2000;23:1339-42.

41 Rith-Najarian S, Branchaud C, Beaulieu O, et al. Reducing lower-extremity amputations due to diabetes: Application of the staged diabetes management approach in a primary care setting. J Fam Pract 1998;47:127-32.

42 Mohamed Q, Gillies MC, Wong TY. Management of diabetic retinopathy: a systematic review. JAMA 2007;298:902-16.

43 Palmer AJ, Roze S, Valentine WJ, et al. The CORE diabetes model: projecting long-term clinical outcomes, costs and cost-effectiveness of interventions in diabetes mellitus (types 1 and 2) to support clinical and reimbursement decision-making. Curr Med Res Opin 2004;20(suppl 1):S5-26.

44 Foos V, Palmer JL, Grant D, et al. PRM58 long-term validation of the IMS CORE diabetes model in type 1 and type 2 diabetes. Value Health 2012;15:A470

45 Waugh N, Scotland G, McNamee P, et al. Screening for type 2 diabetes: literature review and economic modelling. Health Technol Assess 2007; 11:iii-iv, ix-xi, 1-125.

46 Mueller E, Maxion-Bergemann S, Gultyaev D, et al. Development and validation of the Economic Assessment of Glycemic Control and Long-Term Effects of diabetes (EAGLE) model. Diabetes Technol Ther 2006;8:219-36.

47 Majeed A. Sources, uses, strengths and limitations of data collected in primary care in England. Health Stat Q 2004 Spring;(21):5-14.

48 Collins GS, Altman DG. Predicting the 10 year risk of cardiovascular disease in the United Kingdom: independent and external validation of an updated version of QRISK2. BM/ 2012;344:e4181.

49 Collins GS, Altman DG. External validation of the QDScore for predicting the 10-year risk of developing type 2 diabetes. Diabet Med 2011;28:599-607.

(C) BMJ Publishing Group Ltd 2015 